REVISTA DE DERECHO UNED, NÚM. 8, 2011

\title{
BENEFICIOS E INCONVENIENTES (PERJUICIOS) DE LA INSTRUCCIÓN DEL PROCESO PENAL DE MENORES POR EL MINISTERIO FISCAL
}

\author{
MARÍA Nieto LUENGO
}

Resumen: En algunos sucesos acaecidos en los últimos años y como consecuencia de la comisión de determinados delitos (por ejemplo contra la integridad física e integridad sexual, entre otros); han sido imputados, procesados y condenados menores de edad, tras un proceso ordinario que determina la responsabilidad penal de dichos menores. Dicho procedimiento y la responsabilidad que conlleva la comisión de determinados actos, regulados en la LO 5/2000 de Responsabilidad Penal del Menor, (y sus posteriores modificaciones) se encuentran cuestionados.

Este trabajo plantea el análisis de los beneficios y perjuicios (inconvenientes) de que la instrucción se lleve a cabo por el Ministerio Fiscal.

Palabras clave: Proceso penal de menores, instrucción, beneficios, perjuicios, Ministerio Fiscal.

Abstract: In some events in recent years and as a result of the commission of certain crimes (such as against physical and sexual integrity, among others), have been charged, tried and convicted minors, following a judicial process that determines the criminal responsibility of those children. This procedure and the responsibility that comes with the commission of certain acts covered by the LO 5 / 2000 (and subsequent amendments) are questioned. This paper presents the analysis of the pros and cons (disadvantages) that the instruction is carried out by the prosecution. 
Key words: Juvenile criminal trials, training, benefits, damages, public Prosecutor.

Sumario: I. Introducción. II. Proceso Penal. II.1.Funciones del Juez de Instrucción. II.2. Funciones del Ministerio Fiscal. III. Proceso Penal de Menores. III.1.Funciones del Juez de Menores. III.2. Funciones del Ministerio Fiscal. IV. Derecho Comparado. V. Beneficios e inconvenientes de la instrucción del Proceso Penal de Menores por el Ministerio Fiscal. VI. Conclusiones. VII. Normativa citada. VIII. Bibliografía.

\section{INTRODUCCIÓN}

La tesis monista, como es sabido, establece que el proceso penal tiene como función el «ius puniendi» del Estado o «derecho de penar ${ }^{1}$, apareciendo en los sistemas democráticos contemporáneos, la protección del derecho a la libertad, el derecho a la tutela de la víctima y la reinserción del propio imputado ${ }^{2}$.

La función del proceso penal de menores, por el contrario, se centra en obtener la rehabilitación del menor y solucionar el conflicto intersubjetivo entre el agresor y la víctima ${ }^{3}$.

Esta nueva función, añade a los principios del proceso penal, como el principio de proporcionalidad y el de legalidad, entre otros, el principio de interés superior del menor, el de oportunidad y el de intervención mínima.

El principio de interés superior del menor, se enuncia en la Convención sobre Derechos del Niño de 20 de noviembre de 1989 y se instaura también en nuestra Ley Orgánica 5/2000 de Responsabilidad Penal del Menor (LORPM, en adelante).

El principio de oportunidad y el de intervención mínima, íntimamente conectados entre sí, habilitan la posibilidad de no apertura del procedimiento renuncia a mismo, al resarcimiento anticipado o conciliación entre el infractor y la víctima, y a los supuestos de suspensión condicional de la medida impuesta o de sustitución de la

${ }^{1}$ Vid., CALAZa LóPEZ, S., «Garantías constitucionales del proceso judicial español», Ed. Colex, Madrid, 2011.

${ }^{2}$ Vid. Gimeno Sendra, V., Manual de Derecho Procesal Penal, Madrid, Ed. Colex, 2008, pp. 39.

${ }^{3}$ Vid. Gimeno Sendra, V., Manual de Derecho Procesal Penal, Madrid, Ed. Colex, 2008, pp. 468. 
misma durante la ejecución ${ }^{4}$; facultades otorgadas al Ministerio Fiscal, atendiendo a la naturaleza del hecho y a la personalidad del imputado.

El artículo 14.1.del Pacto Internacional de Derechos Civiles y Políticos y 6.1.instauran el derecho que asiste a todos a ser juzgados por un tribunal independiente e imparcial.

El proceso penal de menores que se establece en LORPM, designa al Ministerio Fiscal (en adelante, MF), como «Director de la Instrucción $»^{5}$, dejando al Juez de Menores la emisión de resoluciones limitativas de derechos fundamentales, la fase de juicio oral y la sentencia. En estas fases, queda garantizada la imparcialidad del Juez de Menores que no habrá llevado a cabo ni las diligencias preliminares ni otros actos de investigación que hubieren podido contaminar o condicionar el fallo de su sentencia.

Es por tanto, conveniente analiza, después de los años de implantación de la LORPM, como esta función adquirida por el MF se esta desarrollando y los posibles beneficios o inconvenientes que se deriven de ello, que deriven de que el MF sea el instructor del proceso penal de menores y de la incidencia que puede tener que en otros ordenamientos jurídicos como el alemán, italiano o portugués, en los que ha se ha implantado este nuevo modelo de instrucción llevada a cabo por el Ministerio Público.

\section{PROCESO PENAL}

\section{II.1.Funciones del juez de intrucción}

El artículo 117.1. de nuestra norma suprema, nos dice que «la justicia emana del pueblo y se administra en nombre del Rey por Jueces y Magistrados integrantes en el poder judicial, independientes, inamovibles, responsables y sometidos únicamente al imperio de la ley». Este mismo artículo, en su apartado tercero dispone que «el ejercicio de la potestad jurisdiccional en todo tipo de procesos, juzgando y ha-

${ }^{4}$ Vid. Vázquez González, C., Serrano Tárraga, M.D., Díaz Martínez, M., Lacruz LóPEZ, J.M., Luaces Gutiérrez, A.I., Derecho Penal Juvenil, Madrid, Ed. Dykinson, 2005, pp. 235.

${ }^{5}$ Vid. Gimeno Sendra, V., Manual de Derecho Procesal Penal, Madrid, Ed. Colex, 2008 , pp. 469. Vid., asimismo, Grande Seara, P., Proceso Penal de Menores, Capítulo III, Incoación del Expediente de Reforma y Fase de Instrucción, Ed. Tirant Monografías 628 . 
ciendo ejecutar lo juzgado, corresponde exclusivamente a los Juzgados y Tribunales determinados por las leyes, según las normas de competencia y procedimiento que las mismas establezcan».

Según prosigue el artículo 122 «la ley orgánica del poder judicial determinará la constitución, funcionamiento y gobierno de los Juzgados y Tribunales, así como el estatuto jurídico de Jueces y Magistrados de carrera, ...».

Es por tanto, el ejercicio de la potestad jurisdiccional, la función esencial de los Jueces y Tribunales, juzgando y haciendo ejecutar lo juzgado $^{6}$, función que les corresponde en exclusiva, según las normas de competencia y procedimiento que las leyes establezcan. De esta forma, una vez conocida la «notitia criminis» dentro de los cauces legales establecidos a tal efecto (denuncia o querella por las personas a las que la ley confiere legitimación) y ante los órganos competentes para recibir dicha comunicación del suceso de un hecho delictivo, se «pone en marcha» el proceso y el Juez de Instrucción comienza los actos de investigación e instructorios.

La independencia e imparcialidad que caracteriza la actividad de los Jueces, determina que los actos de prueba, juicio oral y sentencia, sean llevados a cabo por distinto Juez al de Instrucción, que como adelantaba en la introducción no puede verse contaminado o condicionado por los actos anteriores de investigación e instrucción tendentes a preparar el juicio oral.

\section{II.2. Funciones del ministerio fiscal}

El artículo 124.1.de la CE dispone que «El MF tiene como misión promover la acción de la justicia en defensa de la legalidad, de los derechos de los ciudadanos y del interés público tutelado por la ley, de oficio o a petición de los interesados, así como velar por la independencia de los Tribunales y procurar ante éstos la satisfacción del interés social». El apartado segundo de este mismo precepto señala que «El MF ejerce sus funciones conforme a los principios de unidad de actuación y dependencia jerárquica y con sujeción, en todo caso, a los de legalidad e imparcialidad».

Es en el siguiente artículo, 124.3., donde se establece el mandato constitucional de que una ley regule el estatuto orgánico del MF.

${ }^{6}$ Vid., a este respecto, CaLAZA LóPEZ, S. «El binomio procesal. Derecho de acciónDerecho de defensa. Desde una concepción clásica romana hasta la actualidad», Ed. Dykinson, Madrid, 2011. 
El EOMF, en su artículo 1, establece que el MF «tiene como misión promover la acción de la justicia en defensa de la legalidad, de los derechos de los ciudadanos y del interés público tutelado por la ley, de oficio o a petición de los interesados, así como velar por la independencia de los Tribunales, y procurar ante éstos la satisfacción del interés social (conforme al anteriormente citado artículo 124 de la Constitución y Exposición de Motivos de la LOPJ).

Para el cumplimiento de esta misión, se exponen en el capítulo II, las funciones encomendadas al MF. Entre ellas y en relación con el tema objeto de este artículo, podemos señalar: ejercer cuantas funciones le atribuya la ley en defensa de la independencia de los jueces y tribunales; ejercitar las acciones penales y civiles dimanantes de delitos y faltas u oponerse a las ejercitadas por otros, cuando proceda; velar por la protección procesal de las víctimas y por la protección de testigos y peritos, promoviendo los mecanismos previstos para que reciban ayuda o asistencia efectivas; interesar la notificación de cualquier resolución judicial y la información sobre el estado de los procedimientos, ...; visitar en cualquier momento los centros o establecimientos de detención, penitenciarios o de internamiento de cualquier clase de su respectivo territorio, examinar los expedientes de los internos y recabar cuanta información sea conveniente; requerir el auxilio de las autoridades de cualquier clase y de sus agentes; dar a cuantos funcionarios constituyen la Policía Judicial las órdenes procedentes en cada caso; recibir denuncias, enviándolas a la autoridad judicial o decretando su archivo, cuando no encuentre fundamentos para ejercitar acción alguna, notificando en este último caso la decisión al denunciante; para el esclarecimiento de los hechos denunciados o que aparezcan en los atestados de los que conozca, pude llevar a cabo u ordenar aquellas diligencias para las que esté legitimado según la Ley de Enjuiciamiento Criminal, las cuales no podrán suponer la adopción de medidas cautelares o limitativas de derechos. No obstante, podrá ordenar el fiscal la detención preventiva.

Por tanto, el MF puede practicar Diligencias Informativas, encaminadas a la determinación del hecho punible y la responsabilidad del autor.

${ }^{7}$ Vid. Gimeno Sendra, V., Manual de Derecho Procesal Penal, Madrid, Ed. Colex, 2008, pp. 153-154. 
También el MF está obligado a ejercitar la acción civil en el propio interés del perjudicado, salvo que este renuncie o reserve dicha acción civil (legitimación derivada o por sustitución procesal ${ }^{7}$ ).

Todas estas funciones nos conducen a señalar al MF como un órgano activo desde el inicio hasta el fin del proceso, que debe velar no sólo por los derechos e intereses de los ciudadanos, sino también por las correctas actuaciones de Jueces y Tribunales, de su legalidad e independencia.

\section{PROCESO PENAL DE MENORES.}

\section{III.1. Funciones del juez de menores}

Respecto de lo expuesto en el apartado II.1.y en relación al proceso penal de menores, el juez no efectúa la instrucción porque esta función la desempeña el MF.

No obstante, el juez de menores esta presente en la instrucción en cuanto será necesaria su intervención respecto de la adopción de resoluciones limitativas de los derechos fundamentales, decisión sobre medidas cautelares que se soliciten respecto del menor, declaración del secreto instructorio, decisión sobre la apertura del juicio oral o el sobreseimiento, y por supuesto, conocimiento del juicio oral y de la emisión de la pertinente sentencia ${ }^{8}$.

Asimismo, le corresponde intervenir en los actos de prueba sumarial anticipada o preconstituida, prevenir y erradicar las dilaciones en la instrucción y controlar, en general, la actividad en la instructora efectuada por el $\mathrm{MF}^{9}$.

En el proceso penal de menores, se instaura una actuación procesal diferente del proceso penal ordinario respecto de la fase de instrucción pero en ningún momento, el Juez es separado del proceso porque su intervención es necesaria por mandato legal en decisiones sobre medidas a establecer que representen limitaciones en derechos fundamentales además de velar por el correcto cumplimiento de los preceptos legales respecto de la actuación del MF.

${ }^{8}$ Vid. Gimeno Sendra, V., El Ministerio Fiscal-Director de la Instrucción, Madrid, Ed. Iustel, 2006, pp. 51.

${ }_{9}^{9}$ Vid. Gimeno Sendra, V., El Ministerio Fiscal-Director de la Instrucción, Madrid, Ed. Iustel, 2006, pp. 52. 
El Juez de menores no varia respecto del Juez de Instrucción en el proceso penal ordinario y por tanto, al estar presente desde el inicio del proceso, debe mantenerse alejado, dentro de que las circunstancias que se presenten en cada caso concreto se lo permitan (como por ejemplo la gravedad del hecho punible, necesidad de medidas cautelares o el eco social que el delito haya producido), de la instrucción para no viciar su posterior sentencia.

\section{III.2. Funciones del ministerio fiscal}

El EOMF encomienda al MF para el cumplimiento de la misión que tiene atribuida, en relación con el apartado II.2., y específicamente para el Proceso Penal de Menores, entre otras, las siguientes funciones: intervenir en el proceso penal, instando de la autoridad judicial la adopción de medidas cautelares que procedan y la práctica de diligencias encaminadas al esclarecimiento de los hechos o instruyendo directamente el procedimiento en el ámbito de lo dispuesto en la Ley Orgánica reguladora de la Responsabilidad Penal de los Menores, pudiendo ordenar a la Policía Judicial aquellas diligencias que estime oportunas; ejercer en materia de responsabilidad penal de menores las funciones que le encomienda la legislación específica, debiendo orientar su actuación a la satisfacción del interés superior del menor.

Se encomienda también en el EOMF al Ministerio Público el ejercicio de labores que tengan por objeto la protección y defensa de los menores y desvalidos, en general, dentro del juicio y fuera de él, $(\text { artículo 3.7. })^{10}$. Superior vigilancia de la tutela, acogimiento o guarda de los menores, según el artículo 174 del Código Civil, independientemente de cuál sea la nacionalidad de éstos.

Consecuentemente, el MF se convierte en rector de la Instrucción. Le compete practicar la totalidad de los actos de instrucción dirigidos a investigar el hecho punible y la participación del menor, preparando así el juicio oral o proponiendo al Juez del sobreseimiento, dentro de esta fase instrucción, en el Proceso Penal de Menores, Expediente, y distinguiendo dentro de esta fase, Diligencias Preliminares, Decreto de Archivo o Expediente Reformador, así debe vigilar las

\footnotetext{
${ }^{10}$ Instrucción 2/1993, de 15 de marzo, sobre la función del Ministerio Fiscal y el derecho a la intimidad de menores víctimas de un delito.

${ }^{11}$ Vid. Gimeno Sendra, V., Díaz Martínez, M., El Ministerio Fiscal-Director de la Instrucción, Madrid, Ed. Iustel, 2006, pp. 63.
} 
actuaciones en interés del menor y que se respeten todas las garantías del procedimiento, impulsando el mismo ${ }^{11}$.

Respecto del expediente de reforma y según el artículo 6 de la LORPM, corresponde al MF, la defensa de los derechos que a los menores reconocen las leyes.

Adquiere dos roles concurrentes: ser instructor del expediente de reforma y seguir con su función de parte acusadora en el juicio oral ${ }^{12}$, actuando en cada fase por distintos principios como imparcialidad en la fase de instrucción, principio pro societate o en defensa de la sociedad y principio de oportunidad en cuanto a las medidas privativas de derechos. Estos dos roles se mencionan también en la Exposición de Motivos del la LORPM, «la posición del MF es relevante, en su doble condición de institución que constitucionalmente tiene encomendada la función de promover la acción de la justicia y la defensa de la legalidad, así como los derechos de los menores, velando por el interés de éstos».

Igualmente, adquiere una función de mediador, en cuanto al principio del interés superior del menor que ha delinquido y su reinserción y la protección debida a las víctimas. Esta función consiste en su contribución la obtención de una rápida solución tanto del conflicto social existente entre Estado e imputado ${ }^{13}$, cuanto el intersubjetivo entre ofensor y víctima ${ }^{14}$. Podrá así proponer, un acto de conciliación o incluso perdón judicial, siempre y cuando el delito cometido no sea grave, no se haya cometido con violencia o intimidación y el menor no sea reincidente; solicitar sobreseimiento por conciliación o reparación entre menor y víctima o proponer la suspensión del fallo.

Actuaciones estas, consignadas en el articulado de LORPM.

En palabras del Prof. Gimeno Sendra, «el Juez de Instrucción pasa, pues, a desempeñar única y exclusivamente la función de dictar actos jurisdiccionales, en tanto que al MF le corresponde la realización de actos policiales o de investigación $»^{15}$.

${ }^{12}$ Vid. Gimeno Sendra, V., Manual de Derecho Procesal Penal, Madrid, Ed. Colex, 2008, pp. 470.

${ }^{13}$ Vid. Gimeno Sendra, V., El Ministerio Fiscal-Director de la Instrucción, Madrid, Ed. Iustel, 2006, pp. 53.

${ }^{14}$ Vid. Gimeno Sendra, V., Manual de Derecho Procesal Penal, Madrid, Ed. Colex, 2008, pp. 470.

${ }^{15}$ Vid. Gimeno Sendra, V., El Ministerio Fiscal-Director de la Instrucción, Madrid, Ed. Iustel, 2006, pp. 54. 


\section{DERECHO COMPARADO}

La opción adoptada por nuestro legislador, atribuyendo la dirección de la instrucción al MF bajo el control del Juez, ha inspirado las más recientes reformas de la justicia penal en países de nuestro entorno cultural y geográfico, como es el caso de Alemania, Italia y Portugal. La Strafprozessordung de 1877, reformada en 1974, recoge la instrucción de las causas penales a cargo del MF. En Italia, el Codice di Procedura Penale de 1988 encomienda al MF la instrucción del proceso penal y en Portugal, Código de Processo Penal también atribuye esta competencia al $\mathrm{MF}^{16}$.

En el derecho alemán rige el principio de persecución de oficio y el Fiscal posee el monopolio en el ejercicio de la acción penal, referido tanto a la actividad investigadora como a la acusadora. La acción privada se limita a muy pocos delitos y al no existir Juez Instructor, el acusador privado debe llevar a cabo la investigación, lo que resulta prácticamente inviable. La Policía puede iniciar el proceso de la misma forma que el MF, auxiliando a este y al Juez. Tras la reforma operada en 1974, le corresponde al MF, la dirección de la fase de investigación o procedimiento preliminar en el proceso penal. El Juez actúa en casos de peligro de retraso y realiza investigación sin necesidad de solicitud previa a MF o en casos en que este último no pueda intervenir; pero fuera de estos casos por motivos de urgencia, corresponde al Fiscal la dirección de la investigación. En Alemania, el MF se erige en el órgano central de Administración de Justicia y de política criminal ${ }^{17}$.

En Italia, no existe el Juez de Instrucción ni tampoco una instrucción del Juez, es el MF el que con ayuda de la policía judicial desarrolla las investigaciones preliminares de forma libre, manteniendo el respeto a las normas constitucionales. Según el artículo 73 de OJ, el Ministerio Público tiene la misión de velar por la observancia de las leyes y por la pronta y legal administración de justicia; tiene encomendada por tanto, una función de investigación y otra de acusación. Artículo 75, inicia y ejercita la acción penal y un representante del Ministerio Público acude a todas las audiencias. El Juez dispone de las medidas cautelares definitivas y al MF se le reserva el poder de «fer-

${ }^{16}$ Vid. Gimeno Sendra, V., El Ministerio Fiscal-Director de la Instrucción, Madrid, Ed. Iustel, 2006, pp. 78-79-80-81-95.

${ }^{17}$ Vid. Gimeno Sendra, V., El Ministerio Fiscal-Director de la Instrucción, Madrid, Ed. Iustel, 2006, pp. 98-106-107-108-115.

${ }^{18}$ Vid. Gimeno Sendra, V., El Ministerio Fiscal-Director de la Instrucción, Madrid, Ed. Iustel, 2006, pp. 130-131. 
mo (especie de detención en caso de estricta urgencia)», así como la capacidad de archivar, a instancias del MF, las investigaciones preliminares. La policía tiene la obligación de informar al MF sin demora y por escrito de los hechos delictivos de que se trate y sobe los demás elementos recogidos. El Ministerio Público podrá autorizar el secreto de las actuaciones ${ }^{18}$. Se crea la figura del Juez de Investigaciones preliminares cuya misión es controlar las actividades del MF y de la policía judicial y actuar en garantía de los derechos de las partes ${ }^{19}$. Se atribuye también a la defensa y sus delegados, facultades de investigación e indagación ${ }^{20}$ que será libre aunque limitada respecto de las personas ya interrogadas por la policía judicial o el MF.

La fase de investigación en Portugal es la más larga del proceso penal $^{21}$. En el artículo $32.4^{\circ}$ de la Constitución Portuguesa se establece que «la instrucción será competencia de un Juez y la Ley especificará los casos en que aquella deberá revestir forma contradictoria». Sin embargo, el Código del Proceso Penal Portugués, tras la reforma de 1987 (que entre sus objetivos, se destacan por ejemplo, simplificación, rapidez, eficacia y protección de los derechos fundamentales $)^{22}$, atribuye la investigación al Ministerio Público, asistido por los órganos de policía criminal, sumándose así a los países que han optado por reformar la institución del Ministerio Fiscal.

La Constitución y el Código del Proceso Penal establecen dos fases de la etapa preliminar, la primera, obligatoria, de investigación a cargo del MF, y la segunda, eventual, de instrucción a cargo del Juez (respecto de actuaciones que lesionen los derechos fundamentales) ${ }^{23}$.

En España, es la LO 4/1992, que regula la competencia y el procedimiento de los Juzgados de Menores, la que depositó la confianza en el MF para que actuase como instructor y que se ha visto reforzada por la LO 5/2000 y su artículo 16.1.24. Ahora bien, este cambio ne-

${ }^{19}$ Vid. Gimeno Sendra, V., El Ministerio Fiscal-Director de la Instrucción, Madrid, Ed. Iustel, 2006, pp. 147.

${ }^{20}$ Vid. Gimeno Sendra, V., El Ministerio Fiscal-Director de la Instrucción, Madrid, Ed. Iustel, 2006, pp. 209.

${ }^{21}$ Vid. Gimeno Sendra, V., El Ministerio Fiscal-Director de la Instrucción, Madrid, Ed. Iustel, 2006, pp. 209

${ }^{22}$ Vid. Gimeno Sendra, V., El Ministerio Fiscal-Director de la Instrucción, Madrid, Ed. Iustel, 2006, pp. 223.

${ }^{23}$ Circular 1/2000, de 18 de diciembre, relativa a los criterios de aplicación de la Ley Orgánica 5/200, de 12 de enero, por la que se regula la responsabilidad penal de los menores.

${ }^{24}$ Vid. Gimeno Sendra, V., El Ministerio Fiscal-Director de la Instrucción, Madrid, Ed. Iustel, 2006, pp. 34 a 44. 
cesita de una adaptación de algunos aspectos orgánicos del MF al principio de especialización que impone la ley y algunos de los textos internacionales suscritos por nuestro país en relación con esta materia.

A la LO 5/2000 le han sucedido varias reformas. En la LO 8/2006, se establece que tanto por parte del Juez de Menores como del MF, deben velar por la protección de los derechos de las víctimas y de los perjudicados por las infracciones cometidas por los menores.

Se impone en el derecho comparado que sea el MF el que lleve a cabo los actos de investigación e instructorios tanto en el proceso penal ordinario como en el proceso penal de menores. Son bastantes los ordenamientos jurídicos y las regulaciones internacionales en la materia que así lo contemplan.

En base a las actuaciones ya instauradas por los Códigos Procesales Penales relacionados en las líneas precedentes y en nuestra propia legislación, el Profesor GIMENo Sendra, propone entre otras, las siguientes reformas: en la instauración del MF como director de la investigación sumarial, consolidando el principio acusatorio, dotando a la fase de instrucción de mayor rapidez, concediéndole un limitado poder de archivo sometido al principio de oportunidad; reforma de las medidas cautelares; incremento del principio de eficacia; instauración de procesos simplificados; reforma del Jurado e introducción en todos los delitos del derecho al condenado a una segunda instancia ${ }^{25}$.

De implantarse estas reformas se dotaría al proceso penal ordinario, de una mayor agilidad y eficacia, además de descongestionar los juzgados y tribunales españoles de casos no tan graves como los que si necesitan que se habiliten todas las fases del proceso. Ayudaría a este fin, tanto el archivo de determinados casos que igualmente, por sus condiciones de menos graves lo permitan, como el establecimiento de procesos simplificados que consuman menos recursos respecto del tiempo de duración del proceso y económicos, respecto de los costes que un procedimiento más prolongado en el tiempo causa. Estaríamos ante un proceso más acorde con las circunstancias actuales.

\section{BENEFICIOS E INCONVENIENTES DE LA INSTRUCCIÓN DEL}

\footnotetext{
${ }^{25}$ Vid. Gimeno Sendra, V., Díaz Martinez, Manuel., El Ministerio Fiscal-Director de la Instrucción, Madrid, Ed. Iustel, 2006, pp. 54.

${ }^{26}$ Vid. Gimeno Sendra, V., Díaz Martínez, M., El Ministerio Fiscal-Director de la Instrucción, Madrid, Ed. Iustel, 2006, pp. 54-55.
} 


\section{PROCESO PENAL DE MENORES POR EL MINISTERIO FISCAL}

Para analizar los beneficios e inconvenientes que resultan de que la instrucción en el proceso penal la lleve a cabo el MF, hemos de partir de lo establecido en el artículo 117 de nuestra Constitución. Se establece el principio de exclusividad de la jurisdicción ${ }^{26}$.

El artículo 117.3. de la Constitución, se establece, que «el ejercicio de la potestad jurisdiccional («ius puniendi») en todo tipo de procesos, juzgando y haciendo ejecutar lo juzgado, corresponde exclusivamente a los Juzgados y Tribunales ...»

Jueces y Magistrados que según el artículo 117.1.han de ser independientes, inamovibles, responsables y sometidos únicamente al imperio de la ley; que no ejercerán más funciones que las señaladas en estos artículos citados y las que expresamente les sean atribuidas por la ley en garantía de cualquier derecho, 117.4.

Según el Profesor Díaz Martínez, y siguiendo con el análisis del principio de exclusividad, en la investigación penal no se produce ejercicio de la potestad jurisdiccional, no se juzga ni se hace ejecutar lo juzgado, y la intervención judicial sólo se hace necesaria cuando han de adoptarse medidas limitativas de derechos fundamentales ${ }^{27}$.

En base a la precedente afirmación, debo ratificarme, ya que, en mi opinión, en esta actuación del MF no podemos encontrar actos que nos encaminen a pensar que el Ministerio Fiscal juzgue o ejecute lo juzgado, no infringiéndose los principios y funciones constitucionales impuestas tanto a Jueces y Tribunales como al Ministerio Público. No se mezclan los papeles asignados, sino que en el ejercicio de los mismos, cada órgano, realiza los a él, arrogados.

De la misma manera, el juez de instrucción no tendrá que realizar actos de investigación y únicamente tendrá que intervenir en el caso de que se deban adoptar medidas limitativas de los derechos fundamentales.

Al no realizar el juez de instrucción dichos actos de investigación, es difícil que pierda su imparcialidad en el momento de juzgar los hechos y emitir la correspondiente sentencia basada en los mismos. De igual modo que en el proceso penal ordinario, es el juez «a

\footnotetext{
${ }^{27}$ Vid. Gimeno Sendra, V., Díaz Martínez, M., El Ministerio Fiscal-Director de la Instrucción, Madrid, Ed. Iustel, 2006, pp. 56.

${ }^{28}$ Vid. Gimeno Sendra, V., Díaz Martínez, M., El Ministerio Fiscal-Director de la Instrucción, Madrid, Ed. Iustel, 2006, pp. 72.
} 
quo» el que lleva a cabo la fase de instrucción y el juez «ad quem» el que realiza la audiencia, las pruebas y demás actos procesales que le llevarán a emitir una resolución, en el proceso penal de menores, el MF dirige la fase de instrucción y el juez de menores, la audiencia, pruebas y resto de actos procesales.

No podrán convertirse así los actos de investigación en actos de prueba, ya que al MF le esta prohibido establecer actos probatorios ${ }^{28}$. No se produce por tanto una contaminación del juez de menores que pudiera hacer perder su imparcialidad y pudiera entonces condicionarse con los hechos que se van investigando en esta fase del proceso. Se prepara así la acusación y se deja que posteriormente sea, por supuesto el juez, el que en base a todas las pruebas aportadas, decida motivada y congruentemente sobre lo sucedido.

Me reitero en la idea de que esta nueva forma de actuar, establece más agilidad y eficacia al proceso, evitando así posibles vulneraciones de derechos fundamentales en cuanto al juez que ha perdido su imparcialidad y en cuanto a la economía procesal que debe establecerse, ya que si en esta fase de preparación de la acusación e investigación, el MF, establece que continuar con el proceso es innecesario, se procede a la conclusión del mismo dentro de los cauces legales establecidos al efecto.

Asimismo, puede ser beneficioso también que a partir de estos actos de investigación, se produzca la cooperación de los fiscales de otras provincias cuando los hechos delictivos les afecten. Se salvaguardan los derechos establecidos en el artículo 24 de la CE de tutela judicial efectiva.

Aunque lo expuesto hasta aquí nos pudiera hacer pensar que sólo podemos encontrar aspectos positivos a la instrucción por parte del MF, la propia Circular 1/2000 de la Fiscalía del Estado, afirma que se debe adecuar a esta nueva función que se atribuye al Ministerio Público, adoptándose diferentes criterios organizativos de los que hasta ahora se venían utilizando y un reparto de trabajo entre los componentes que estén adscritos a la Fiscalía de Menores, sin quebrar por ello el principio de unidad de actuación que deben respetar.

Otro de los inconvenientes pudiera ser, y según el Profesor Díaz Martínez, la petición de sobreseimiento que puede realizar el MF plantea la duda de si el Juez de Menores posee facultades correctoras

${ }^{29}$ Vid. Gimeno Sendra, V., Díaz Martínez, M., El Ministerio Fiscal-Director de la Instrucción, Madrid, Ed. Iustel, 2006. 
y de fiscalización que el procedimiento común asigna al órgano jurisdiccional en los artículos 642 y 644 LECRIM $^{29}$.

Es cierto que la LO 5/2000, faculta al MF al desistimiento de la incoación del expediente por corrección en el ámbito educativo y familiar (artículo 18), siempre y cuando nos encontremos ante delitos menos graves sin violencia o intimidación en las personas, faltas, y siempre que con anterioridad no se hayan cometido hechos de la misma naturaleza; dando traslado de lo actuado a la entidad pública de protección de menores que actuará según lo establecido en le artículo 4 de dicha ley. El sobreseimiento puede venir en base al artículo 19, por conciliación o reparación del menor y la víctima, siempre y cuando se den las circunstancias descritas en el anterior artículo 18, respecto de la menor gravedad del hecho o falta de violencia o intimidación.

El artículo 30.4. de LORPM establece que también este sobreseimiento se puede solicitar al juez por los motivos previstos entre los artículos 637 y 641 de la LECrim.

Estos últimos motivos expuestos en el articulado citado de la LECrim, entiendo no pueden llevarnos a la misma conclusión que el análisis del desistimiento y sobreseimiento que establece la LORPM. En el primer supuesto, el sobreseimiento procederá «cuando se entienda que no hay indicios racionales de haberse perpetrado el hecho que hubiera dado motivo a la formación de la causa; cuando el hecho no sea constitutivo de delito o cuando los procesados se hallen exentos de responsabilidad criminal». En estos casos, la renuncia a iniciar el proceso por parte del MF, esta totalmente justificada, ya que en caso contrario se podría vulnerar el derecho de defensa, entre otros derechos fundamentales. Se suma a este razonamiento, el hecho que la petición del MF esta supervisada y controlada por el Juez o Tribunal competente al efecto. Es así, que quien juzga o valora, y emite la resolución final sea el Juez o Tribunal, no vulnerándose ni los principios constitucionales ni los preceptos legales instaurados.

La duda puede surgir acerca de lo establecido en la LORPM, ¿está el MF dictaminando el hecho en base a las investigaciones realizadas, es decir, esta valorando los hechos y juzgando? El desistimiento y sobreseimiento enunciado en dicha ley, es un pronunciamiento del MF sin intervención alguna del Juez de Menores. ¿Enjuicia o ejercita las funciones que legalmente le han sido establecidas? Yo me inclino por esta última opción, ya que en caso contrario estos preceptos estarían vulnerando los derechos de los menores infractores a un pro- 
ceso debido con todas las garantías que se establecen tanto el artículo 24 como 117 de nuestra Constitución.

\section{CONCLUSIONES}

Tras esta aproximación a la Instrucción que lleva a cabo el MF desde que se implantó la ley 5/2000, respecto del proceso penal de menores, podemos afirmar lo beneficioso que puede ser que dicha actuación así se realice en el proceso penal ordinario.

Superados los inconvenientes que la adaptación organizativa que se ha debido efectuar y la duda que surgía respecto de la actuación cuasi judicial del MF en el caso de desistimiento de incoación del expediente por corrección en el ámbito educativo y familiar y el sobreseimiento del expediente por conciliación o reparación entre el menor y la víctima, considero que esta modificación que se ha llevado a cabo es completamente positiva en el desarrollo del proceso.

Las funciones establecidas para el Juez de Menores y para el MF en ningún momento se cruzan, las de uno no desvirtúan las del otro y viceversa. El MF realizando los actos de instrucción no juzga y se consigue mantener la imparcialidad de ambos órganos, interviniendo cada uno en las distintas fases del proceso.

El MF se configura como órgano activo en la vida del proceso y debe velar por los derechos de los ciudadanos y las garantías debidas de un procedimiento justo, las garantías, actuando e interviniendo en las diligencias y fases como defensor de la legalidad, promoviendo la acción de la justicia y asistiendo al objetivo primordial de este proceso penal de menores, rehabilitación del menor y solución del conflicto intersubjetivo entre agresor y víctima.

Se garantiza así, además de los derechos fundamentales de los menores infractores, otros como el de economía procesal, en cuanto a la agilidad y rapidez con la que se puede proceder en la determinación de los delitos más graves y los que no hagan necesario que se active el proceso judicial, así como el respeto a principios como el de imparcialidad, oportunidad, interés superior del menor, intervención mínima y acusatorio, entre otros.

Es por tanto, que el Juez puede emitir una sentencia, en caso de que se estime necesario que el proceso continúe hasta su fase final, por no haberse desestimado la pretensión o sobreseído la causa, no habiendo visto pervertido su criterio ya que a él llegan los actos de in- 
vestigación y de instrucción para dar comienzo la fase intermedia o alegaciones y audiencia.

Por todo esto, en otros ordenamientos jurídicos cercanos al nuestro (así, el alemán, italiano o portugués, como ejemplo), se ha establecido el sistema del MF como director de la instrucción y no sólo en el proceso penal de menores como en España, sino en procesos penales ordinarios, advirtiendo a priori las consecuencias positivas que acarrea.

Por todo lo expuesto, estimo apropiadas y convenientes las medidas de reforma que propone el Profesor GiMENo Sendra, mencionadas anteriormente en el apartado III, que nos llevarían a un incremento de las plantillas, su desconcentración y adscripción a todos los juzgados de Instrucción, incrementando la celeridad de esta fase ${ }^{30}$, entre otras ventajas.

\section{NORMATIVA CITADA}

\section{Convenios Internacionales}

Convención sobre Derechos del Niño de 20 de noviembre de 1989, Naciones Unidas. 1950.

Convenio Europeo de Derechos Humanos, Consejo de Europa,

Pacto Internacional de Derechos Civiles y Políticos, Asamblea General de Naciones Unidas, de 16 de diciembre de 1966.

\section{Legislación Estatal}

Circular 1/2000, de 18 de diciembre, relativa a los criterios de aplicación de la Ley Orgánica 5/2000, de 12 de enero, por la que se regula la responsabilidad penal de los menores.

Circular 3/2001, de 21 de diciembre, sobre actuación del Ministerio Fiscal en materia de extranjería.

Circular 1/2007 sobre criterios interpretativos tras la reforma de la legislación penal de menores de 2006.

${ }^{30}$ Vid. Gimeno Sendra, V., Díaz Martínez, M., El Ministerio Fiscal-Director de la Instrucción, Madrid, Ed. Iustel, 2006. 


\section{Código Civil.}

Constitución Española de 1978.

Instrucción 2/1993, de 15 de marzo, sobre la función del Ministerio Fiscal y el derecho a la intimidad de los menores víctimas de un delito.

Instrucción 1/2005, sobre instrumentación efectiva del principio de actuación establecido en el artículo 124 de la Constitución.

Instrucción 2/2006, sobre el Fiscal y la protección del derecho al honor, intimidad y propia imagen de los menores.

Ley Orgánica 50/1981, de 30 de diciembre, por la que se regula el Estatuto Orgánico del Ministerio Fiscal.

Ley Orgánica 6/1985, de 1 de julio, del Poder Judicial.

Ley Orgánica 4/1992, de 5 de junio, por la que se regula la competencia y procedimiento de los Juzgados de Menores.

Ley Orgánica 5/2000 de Responsabilidad Penal del Menor.

Ley Orgánica 8/2006, de 4 de diciembre, por la que se modifica la LO 5/2000, de 12 de enero, reguladora de la responsabilidad penal de los menores.

Real Decreto de 14 de septiembre de 1882, aprobatorio de la Ley de Enjuiciamiento Criminal.

\section{BIBLIOGRAFIA}

Calaza López, S., «Garantías constitucionales del proceso judicial español», Ed. Colex, Madrid, 2011.

Calaza LóPEZ, S. «El binomio procesal. Derecho de acción-Derecho de defensa. Desde una concepción clásica romana hasta la actualidad», Ed. Dykinson, Madrid, 2011.

Gimeno Sendra, V., Manual de Derecho Procesal Penal, Madrid, Ed. Colex, 2008.

Gimeno Sendra, V., El Ministerio Fiscal-Director de la Instrucción, Madrid, Ed. Iustel, 2006.

Grande Seara, P., Proceso Penal de Menores, Capítulo III, Incoación del Expediente de Reforma y Fase de Instrucción, Ed. Tirant Monografías. 
Vázouez González, C., Serrano Tárraga, M. D., Díaz Martínez, M., Lacruz López, J. M. Y Luaces Gutiérrez, A. I., Derecho Penal Juvenil, Madrid, Ed. Dykinson, 2005. 